\title{
REGISTROS ACÚSTICOS BIOLÓGICOS DETECTADOS NA ZONA ECONÔMICA EXCLUSIVA DA REGIÃO NORDESTE DO BRASIL - UMA CLASSIFICAÇÃO EM ECOTIPOS FUNCIONAIS
}

\author{
STEFAN CRUZ WEIGERT ${ }^{1} \&$ LAURO SAINT PASTOUS MADUREIRA ${ }^{2}$ \\ ${ }^{1}$ Centro de Pesquisa e Gestão dos Recursos Pesqueiros Estuarinos e Lagunares - CEPERG/ICMBio - Rua Visconde de Paranaguá, \\ s/n - CP 357 - Rio Grande, RS, Brasil CEP 96200-190 - stefan.weigert@icmbio.gov.br. \\ 2Instituto de Oceanografia/Laboratório de Tecnologia Pesqueira/Universidade Federal do Rio Grande - Av. Itália s/no Km 08 CP 474 \\ Campus Carreiros Rio Grande, RS, Brasil CEP 96203-000 - doclsm@furg.br
}

\begin{abstract}
Um cruzeiro de prospecção hidroacústica foi realizado ao longo da plataforma, talude e região oceânica adjacente da costa Nordeste do Brasil, incluindo Bancos Oceânicos do Ceará, Atol das Rocas e Arquipélagos de Fernando de Noronha e de São Pedro e São Paulo. Foram prospectadas 1.653 milhas náuticas para avaliar distribuição e abundância de espécies de pequenos peixes pelágicos. Dados hidroacústicos foram coletados com uma ecossonda científica SIMRAD EK 500 operando em $38 \mathrm{kHz}$. Os registros gráficos foram utilizados para a caracterização morfológica dos agrupamentos de organismos. Dados de densidade acústica e amostras de rede de arrasto pelágico foram analisados buscando padrões que permitissem agrupar os registros em ecotipos. Os eco-registros detectados na ZEE da região Nordeste do Brasil foram organizados e caracterizados, baseando-se em descritores energéticos, morfológicos, espaciais, temporais e biológicos em cinco ecotipos funcionais representados por diferentes assembléias de espécies: 1) Nerítico; 2) Camada Oceânica; 3) Myctophidae; 4) Camada Oceânica com Myctophidae; e 5) Nuvem de Quebra (de Plataforma). A forma de agregação biológica tipicamente registrada na região foram as Camadas de Dispersão Acústica (CDA), tanto superficialmente quanto em estratos profundos da coluna de água. Movimentos de migração nictemeral relacionados às CDAs foram frequentemente observados, sendo de destacada importância ecotrófica para a região.
\end{abstract}

PALAVRAS CHAVE: Camada de Dispersão Acústica, costa Nordeste do Brasil, ecotipo, migração nictemeral, Zona Econômica Exclusiva.

\section{ABSTRACT \\ Biological scatterers detected along the Exclusive Economic Zone of northeast Brazilian coast, a classification of echo-records into functional echo-types}

One hydroacoustics cruise was carried out along the shelf, shelf-break and oceanic adjacent waters along the northeastern Brazilian coast and the oceanic banks of Ceará, Rocas Atoll, and Fernando de Noronha and São Pedro and São Paulo archipelagos. A total of 1.653 nautical miles were assessed in order to investigate the distribution and abundance of small pelagic fishes. Hydroacoustics data were collected with a Scientific Echo-sounder EK 500, operating at $38 \mathrm{kHz}$. The acoustic records were stored as digital echograms from where morphological information about the scatterers aggregated into acoustic layers could be obtained. Also, acoustic density proportional to biological density were collected as well as biological samples using a mid water trawl net. Data were processed in order to identify patterns of echo-records which resulted in the classification of five functional echo-types represented by different species assemblies: 1) Neritic; 2) Oceanic layer; 3) Myctophidae; 4) Oceanic layer with Myctophidae; and 5) Shelf Break Plume. Sound Scattering Layers (SSLs) were the typical biologic aggregation structures registered in the area, as much superficially as in deep strata of water column. Nycthemeral migrations related to the SSL were frequently observed, being of great ecotrophic importance for the area.

KEYWORDS: echo-type, Exclusive Economic Zone, nycthemeral migration, Northeast brazilian coast, Sound Scattering Layer.

\section{INTRODUÇÃO}

A hidroacústica caracteriza-se como um método não invasivo que permite o estudo de extensas áreas em períodos relativamente curtos de tempo, sendo utilizada para mapeamentos da distribuição e estimativas de abundância de recursos pesqueiros pelágicos, tais como peixes, lulas, krill e estudos de interações entre espécies (Mitson 1983, Gerlotto 1993, Goss et al. 2001, Madureira \& RossiWongtschowski 2005). O método proporciona informações contínuas e detalhadas da coluna de água e do leito oceânico, através da transmissão de ondas sonoras que se propagam verticalmente e atingem refletores acústicos, biológicos ou não, com posterior recepção, processamento e armazenagem dos ecos de retorno (Simmonds \& MacLennan 2005).

Em cruzeiros de prospecção hidroacústica são realizadas varreduras ao longo de perfis previamente definidos. Os dados são armazenados digitalmente sob a forma de matrizes numéricas e ecogramas. Os ecogramas correspondem à representação gráfica dos dados coletados pela sonda, sendo sua análise considerada o passo inicial para qualquer processamento de sinais hidroacústicos a ser desenvolvido (Reid et al. 2000, Madureira \& Rossi-Wongtschowski 2005).

Durante cruzeiros de hidroacústica um volume considerável de informações é coletado e armazenado. Estas informações devem ser organizadas e associadas a características espécie-dependentes dos organismos que compõe os eco-registros.

Considerando-se que existe correlação entre a refletividade acústica $e$ as características anatômicas (taxonômicas e biométricas), fisiológicas e comportamentais dos organismos detectados, padrões que se mantêm relativamente constantes nos eco-registros indicam a presença de determinadas 
espécies ou assembléias de organismos (Gerlotto \& Marchal 1985). Da mesma forma, variações nas características dos organismos resultam na alteração dos padrões observados nos eco-registros e, por esse motivo, a utilização de descritores apropriados é determinante para a sua classificação (Petitgas \& Levenez 1996). O termo ecotipo é utilizado para representar tais padrões (Madureira \& RossiWongtschowski 2005). Tendo em vista o enfoque ecológico utilizado na análise e discussão dos resultados no presente estudo, não se restringindo o mesmo a uma simples classificação dos ecoregistros, foi adotada a terminologia "ecotipo funcional".

Levantamentos de distribuição e abundância de espécies pelágicas com método hidroacústico tiveram início no Brasil em 1974, a partir de uma série de cruzeiros executados na costa sudeste e sul, cujos principais objetivos foram de identificar e quantificar pequenos peixes pelágicos como sardinha verdadeira (Sardinella janeiro) e anchoita (Engraulis anchoita) (Rijavec \& Amaral 1977, Matsuura et al. 1985, Castello et al. 1991, Lima \& Castello 1994, Castello 1997), e do calamar argentino (Illex argentinus) (Rahn \& Santos 1978)

Estudos mais recentes, visando especificamente um melhor entendimento da diversidade, distribuição e abundância dos recursos vivos da costa brasileira foram efetuados com base nas necessidades do Programa de Avaliação do Potencial Sustentável de Recursos Vivos na Zona Econômica Exclusiva (REVIZEE). Tais estudos resultaram no reconhecimento e caracterização de nove ecotipos para a costa Central (Madureira et al. 2004), e seis para a costa Sudeste/Sul do Brasil (Madureira \& Rossi-Wongtschowski 2005).

O presente estudo está baseado nos dados coletados ao longo de um cruzeiro de pesquisa executado na região Nordeste da ZEE do Brasil, e representa uma extensão para norte da área total coberta com emprego da metodologia hidroacústica, no âmbito do Programa REVIZEE.

O ambiente oceanográfico da região Nordeste é dominado pelo sistema de correntes Sul Equatorial (CSE), que flui entre os paralelos $10^{\circ}$ e $25^{\circ} \mathrm{S}$ em direção à costa brasileira (Stramma 1991) próxima da qual se bifurca originando a Corrente Norte do Brasil
(CNB), que segue rumo às Guianas, e a Corrente do Brasil (CB), na direção sul. Tal bifurcação ocorre quando a CSE encontra a massa continental do território brasileiro, ao sul da latitude 10오 (Peterson \& Stramma 1991, Castro \& Miranda 1998, Ekau \& Knoppers 1999, Silveira et al. 2000). As massas de água predominantes são a Água Tropical (AT), que ocupa a camada superficial até cerca de $200 \mathrm{~m}$ de profundidade, a Água Central do Atlântico Sul (ACAS), imediatamente abaixo da AT, até cerca de $700 \mathrm{~m}$ (Silva \& Alvarenga 1996a-b, Nonaka et al. 2000, Geber 2003), e a Água Intermediária Antártica (AIA) posicionada abaixo da ACAS e atingindo uma profundidade máxima de cerca de $1300 \mathrm{~m}$ (Medeiros et al. 2009b). Água Profunda do Atlântico Norte (APAN) e Água Antártica de Fundo (AAF) são também reportadas para a área, ocupando camadas oceânicas profundas (Stramma \& Schott 1999). De acordo com Medeiros et al. (2009b) não foram observadas influências significativas dos aportes continentais através da presença de águas com baixas salinidades.

A estrutura termohalina da ZEE Nordeste é estável, com flutuações sazonais de pequena magnitude para a camada superficial (Medeiros et al. 2009a). Uma termoclina fortemente definida se faz presente durante todo o ano na região, com seu topo situado entre 50 e $100 \mathrm{~m}$ de profundidade, separando a AT da ACAS (Travassos et al. 1999). Medeiros et al. (2009a) observam que a profundidade de topo da termoclina aumenta com a latitude e com a proximidade da costa.

A área se enquadra no denominado Grande Ecossistema Marinho do Leste do Brasil (East Brazilian Large Marine Ecosystem) (Ekau \& Knoppers 1999). A região possui uma teia alimentar complexa, com produtividade biológica baixa, sendo considerada a mais oligotrófica da Zona Econômica Exclusiva (ZEE) brasileira, com reduzidos níveis de nutrientes e biomassas fitoplanctônicas e zooplanctônicas (Becker 2001, Medeiros et al. 1999, Neumann-Leitão et al. 1999), apresentando uma estreita faixa de concentração mais elevada de clorofila-a ao longo da costa (Ferreira \& Travassos 2009).

De acordo com Ekau \& Knoppers (1999) e Travassos et al. (1999), na região oceânica, nas proximidades de ilhas e montes submarinos ocorrem 
ressurgências topográficas que promovem a ascensão de águas profundas ricas em nutrientes, com consequente enriquecimento superficial localizado.

Nesse contexto destaca-se a importância ecológica de estruturas denominadas camadas de dispersão acústica (CDA), que são comumente observadas em grande abundância em regiões de bancos submarinos e talude (Pusch et al. 2004).

As camadas compostas por organismos micronectônicos são um componente importante dos ecossistemas oceânicos, sendo responsáveis pelo consumo de uma porção significativa da produção zooplanctônica (Clarke 1973). Esses organismos realizam a transferência de energia para níveis tróficos superiores e também entre estratos batimétricos (Rasmussen \& Giske 1994). Muitos dos organismos componentes das CDA são conhecidos por realizarem migrações nictemerais (Mosgovoy \& Becker 1991), ocupando estratos verticais mais profundos durante o dia, e deslocando-se dezenas a centenas de metros em direção à superfície durante a noite (Longhurst 1976).

Estudos evidenciam ainda que, além do deslocamento vertical, os organismos deslocam-se horizontalmente (Reid et al. 1991), sendo que, em termos de velocidade, essa componente atinge uma ordem de magnitude até 2 vezes maior do que a primeira (Benoit-Bird \& Au 2004). A combinação entre os deslocamentos vertical e horizontal dos organismos formadores das CDA promove uma importante ligação trófica e ecológica entre ambientes neríticos e oceânicos, especialmente nos entornos de ilhas oceânicas, montes submarinos e regiões de quebra da plataforma continental (Benoit-Bird et al. 2001, Benoit-Bird \& Au 2004, Cartes et al. 2009).

Evidências da interação trófica entre os organismos que realizam migração nictemeral e a fauna local são amplamente apresentadas na literatura (Gordon \& Mauchline 1990, Mauchline \& Gordon 1991, Cartes 1994, Fock et al. 2002, Cartes et al. 2009). Tais evidências são apresentadas também por Vaske Jr. et al. (2008) a partir da mesma base de dados utilizada para este estudo.

O presente estudo tem por objetivos organizar, descrever e classificar os eco registros obtidos na região Nordeste do Brasil, caracterizandoos em ecotipos funcionais, e discutir as implicações ecológicas dos resultados, comparativamente com estudos similares realizados nas regiões Sudeste/Sul e Central do Brasil.

\section{MATERIAL E MÉTODOS}

Um cruzeiro de prospecção hidroacústica foi realizado nos meses de maio e junho de 2004, a bordo do Navio Oceanográfico Atlântico Sul, da Universidade Federal do Rio Grande (FURG). O desenho amostral (Figura 1) foi organizado de forma a prospectar áreas sobre as plataformas, os taludes e regiões oceânicas adjacentes dos Arquipélagos de Fernando de Noronha, de São Pedro e São Paulo, do Atol das Rocas e dos Bancos Oceânicos do Ceará, além da plataforma continental e talude compreendidos entre Fortaleza, CE (034' S) e a

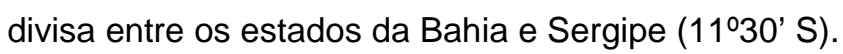

Durante a prospecção foi utilizada uma ecossonda científica digital com ecointegrador SIMRAD EK500, acoplada a um transdutor de casco tipo split beam, operando na frequência de $38 \mathrm{kHz}$. Os limiares de energia acústica para aquisição de dados e impressão de ecogramas, e a duração do pulso acústico foram configurados em -80 e -65 decibéis $(\mathrm{dB})$, e 1,0 milisegundo (ms), respectivamente. A profundidade de operação esteve compreendida entre 5 e 500 m, tendo sido utilizado um coeficiente de atenuação de $10 \mathrm{~dB} / \mathrm{km}$. Os dados hidroacústicos foram digitalmente armazenados sob a forma de ecogramas através do software MOVIES + versão 3.4b (IFREMER), e de arquivos numéricos, para posterior processamento. 


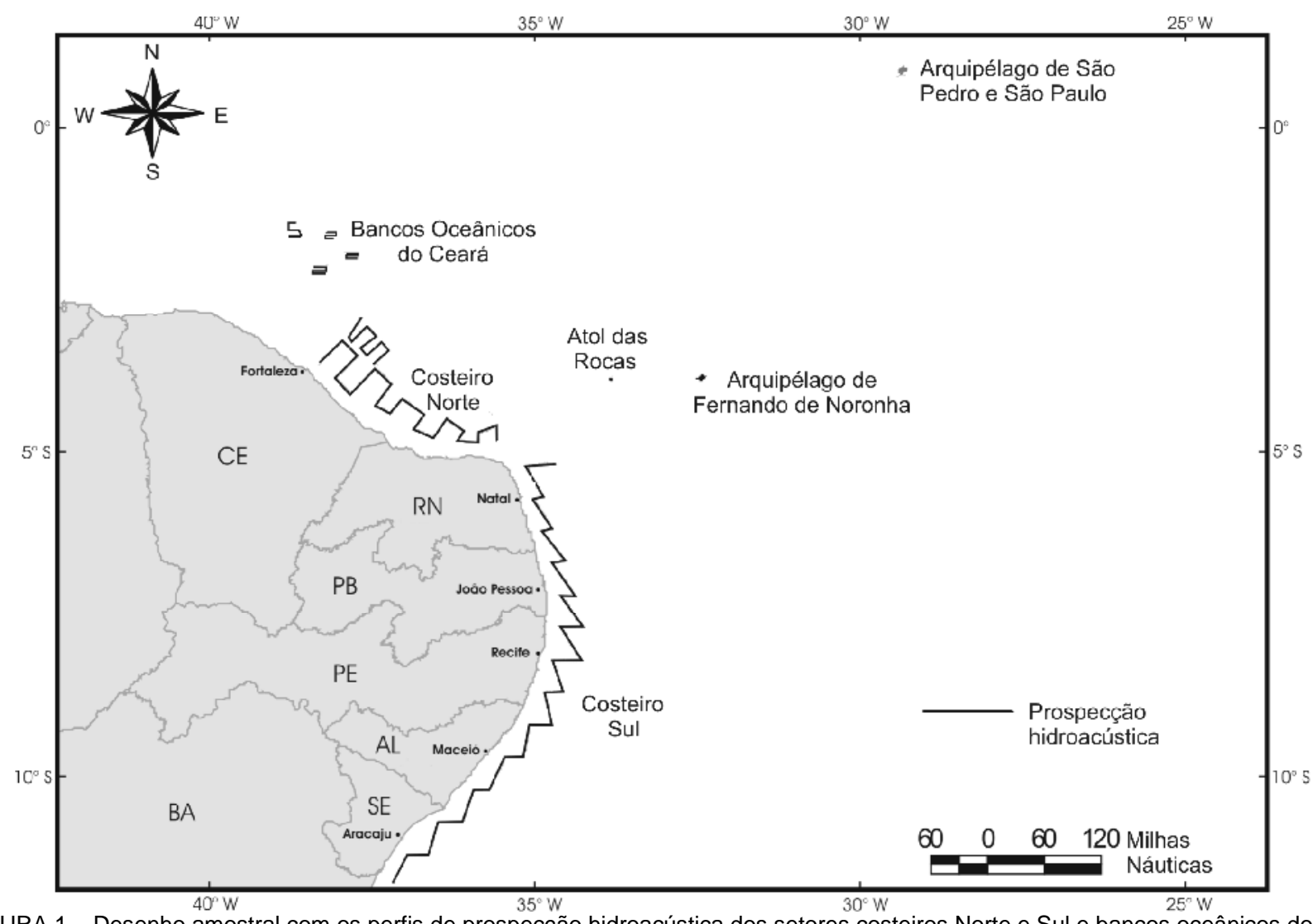

FIGURA 1 - Desenho amostral com os perfis de prospecção hidroacústica dos setores costeiros Norte e Sul e bancos oceânicos do Ceará, e a localização geográfica do Atol das Rocas e dos Arquipélagos de Fernando de Noronha e de São Pedro e São Paulo.

A varredura acústica foi realizada ao longo das 24 horas do dia, sendo interrompida apenas para a realização de lances de pesca e coleta de dados ambientais. A separação dos dados por períodos do dia foi realizada de acordo com os horários de nascer e pôr do sol, consultados no sítio do Portal Oceanografia Naval (Naval Oceanography Portal http://www.usno.navy.mil/usno/astronomicalaplications), para as datas e posições geográficas correspondentes ao local onde o navio estava trabalhando. Os períodos foram definidos como "dia" - do nascer ao pôr do sol e "noite" - entre os crepúsculos vespertino e matutino.

Antes do início do cruzeiro a eco sonda foi calibrada de acordo com o método da Esfera Padrão (Foote, 1982; Simmonds \& MacLennan, 2005), na Enseada do Portão (03ํ52,55'S / 032²8,13'W), Arquipélago de Fernando de Noronha.

O processamento dos dados acústicos consistiu inicialmente na interpretação visual dos ecogramas, na definição e descrição dos padrões de eco registros o que permitiu sua classificação em ecotipos. Para a caracterização dos ecotipos foram utilizados descritores energéticos, morfológicos, espaciais, temporais e, sempre que possível, biológicos, conforme metodologia descrita por Madureira \& Rossi-Wongtschwski (2005).

O descritor energético é avaliado através do parâmetro Coeficiente de Espalhamento Acústico por Área Náutica (Nautical Area Scattering Coefficient) ou NASC, proporcional à densidade acústica de organismos detectados e expressa em unidades de área (MacLennan et al. 2002). Os descritores morfológico, espacial e temporal estão relacionados respectivamente ao tipo de eco-traço (forma, extensões horizontal e vertical) e grau de agrupamento (cardumes/camadas dispersos ou compactos), localização geográfica e batimétrica do eco-registro, e data e hora em que o registro foi realizado. $O$ descritor biológico advém de amostragens dos organismos detectados pela ecossonda.

A rede utilizada é do tipo arrasto de meia água com asas e quadrado com malha de $400 \mathrm{~mm}$ entre nós opostos, diminuindo gradativamente para $50 \mathrm{~mm}$ no túnel e $20 \mathrm{~mm}$ no saco e saco interno com 
malha de $6 \mathrm{~mm}$. Para a abertura de $15 \times 15 \mathrm{~m}$ da boca da rede foram utilizadas portas pelágicas do tipo Süberkrüb, com 4,0 $\mathrm{m}^{2}$ de superfície $(3,0 \times 1,35 \mathrm{~m})$ e peso aproximado de $380 \mathrm{~kg}$ cada. $\mathrm{O}$ desempenho da rede e o sucesso das capturas foram monitorados através de uma sonda de rede SIMRAD FS903 Trawl Sonar, cujo transdutor estava disposto na tralha superior e conectado ao navio por cabo eletromecânico acoplado a guincho especifico.

Durante as operações de pesca a velocidade da embarcação variou entre 3 e 4 nós e o tempo de arrasto foi dependente do posicionamento dos alvos e de eventuais modificações na profundidade de operação da rede ao longo de um mesmo lance. De posse dessas informações foi avaliada a profundidade da rede e do eco registro e se o lance desenvolveu-se de forma correta, em cada operação de pesca. Em todos os casos onde a rede operou na profundidade pretendida, e nos quais a observação do registro foi adequada, os lances foram considerados representativos (Tabela 1), e classificados a partir da composição de suas capturas e das características do registro-alvo.
As amostras foram processadas no Laboratório de Dinâmica de Populações Marinhas (DIMAR), da Universidade Federal Rural de Pernambuco (UFRPE), para identificação dos organismos capturados e avaliação da representatividade de cada espécie e respectivas classes de tamanho dos indivíduos. Os resultados foram apresentados por Vaske Jr. et al. (2005).

Trechos de ecogramas representativos de cada um dos ecotipos classificados foram selecionados e apresentados nas figuras 2 a 8 , sendo que os eco-traços de interesse encontram-se destacados por um polígono tracejado. Tons de cinza mais escuros nos ecogramas estão relacionados a valores relativamente mais elevados de densidade acústica.

Para comparações de densidade acústica foi utilizado o teste não-paramétrico de Mann-Whitney, onde a significância do parâmetro $U$ é dada pelo valor $z$, através do qual se obtém o valor de $p$, estabelecido o nível de significância de $5 \%$.

TABELA 1 - Posições dos lances de pesca referenciados aos setores do cruzeiro, com data, horário inicial, profundidade local e profundidade de operação da rede.

\begin{tabular}{|c|c|c|c|c|c|c|}
\hline & & \multirow[b]{3}{*}{ Hora inicial } & \multirow{2}{*}{\multicolumn{2}{|c|}{ Posição inicial }} & \multirow{2}{*}{\multicolumn{2}{|c|}{ Profundidade (m) }} \\
\hline \multirow[b]{2}{*}{ Setor } & \multirow[b]{2}{*}{ Dia/mês } & & & & & \\
\hline & & & Latitude & Longitude & \multicolumn{2}{|r|}{ Amostra } \\
\hline \multirow[b]{2}{*}{ São Pedro e São } & $30 / 04$ & $16: 33$ & $00^{\circ} 55,02^{\prime} \mathrm{N}$ & $029^{\circ} 19,16^{\prime} \mathrm{W}$ & 602 & $40-85$ \\
\hline & $30 / 04$ & $20: 45$ & $00^{\circ} 57,39^{\prime} \mathrm{N}$ & $029^{\circ} 21,20^{\prime} \mathrm{W}$ & 1720 & $45-90$ \\
\hline \multirow[t]{2}{*}{ Paulo } & $01 / 05$ & $17: 24$ & $00^{\circ} 57,00^{\prime} \mathrm{N}$ & $029^{\circ} 19,64^{\prime} \mathrm{W}$ & 1480 & $30-75$ \\
\hline & $01 / 05$ & $21: 15$ & $00^{\circ} 56,17^{\prime} \mathrm{N}$ & $029^{\circ} 20,44^{\prime} \mathrm{W}$ & 1015 & $50-90$ \\
\hline Atol das Rocas & $03 / 05$ & $21: 13$ & $03^{\circ} 50,40^{\prime} \mathrm{S}$ & $033^{\circ} 46,07^{\prime} \mathrm{W}$ & 65 & $55-100$ \\
\hline \multirow{3}{*}{ Bancos do Ceará } & $09 / 05$ & $14: 05$ & $03^{\circ} 23,59^{\prime} \mathrm{S}$ & $037^{\circ} 24,81^{\prime} \mathrm{W}$ & 255 & $110-180$ \\
\hline & $10 / 05$ & 01:35 & $03^{\circ} 14,61^{\prime} \mathrm{S}$ & $037^{\circ} 44,54^{\prime} \mathrm{W}$ & 1950 & $100-120$ \\
\hline & $12 / 05$ & $04: 54$ & $03^{\circ} 12,70^{\prime} \mathrm{S}$ & $038^{\circ} 24,48^{\prime} \mathrm{W}$ & 385 & $80-110$ \\
\hline Costeiro Norte & $17 / 05$ & $02: 50$ & $04^{\circ} 42,46^{\prime} \mathrm{S}$ & $035^{\circ} 32,53^{\prime} \mathrm{W}$ & 95 & $70-90$ \\
\hline \multirow{3}{*}{ Costeiro Sul } & $28 / 05$ & 19:20 & $06^{\circ} 40,64^{\prime} \mathrm{S}$ & $034^{\circ} 31,69^{\prime} \mathrm{W}$ & 2300 & $100-145$ \\
\hline & $28 / 05$ & $20: 24$ & $06^{\circ} 38,92^{\prime} \mathrm{S}$ & $034^{\circ} 35,18^{\prime} \mathrm{W}$ & 1650 & $20-40$ \\
\hline & $29 / 05$ & $21: 07$ & $08^{\circ} 11,60^{\prime} \mathrm{S}$ & $034^{\circ} 36,02^{\prime} \mathrm{W}$ & 50 & $25-60$ \\
\hline
\end{tabular}

FONTE: Stefan Cruz Weigert

Ecotipos funcionais da ZEE Nordeste do Brasil 
Além dos 12 lances de pesca representativos dos eco registros, outros quatro lances resultaram em captura nula, não tendo sido considerados na análise.

Perfis verticais de temperatura e salinidade, entre a superfície e a profundidade máxima de aproximadamente $600 \mathrm{~m}$, foram obtidos através de um micro CTD FSI (Falmouth Scientific, Inc.) devidamente calibrado. Foram realizadas 71 estações oceanográficas de coleta de dados ambientais distribuídas ao longo da área de estudo, à exceção do Arquipélago de Fernando de Noronha, que não constou como área de amostragem ambiental e biológica no planejamento do cruzeiro, e do setor Costeiro Sul, etapa na qual o equipamento não esteve disponível a bordo. Os resultados relativos da análise dos dados ambientais foram apresentados por Weigert (2006) e Madureira et al. (2009) e serão ora abordados para a discussão dos resultados da caracterização dos registros acústicos em ecotipos funcionais da ZEE do Nordeste do Brasil.

\section{RESULTADOS}

A partir da análise dos eco registros e seus respectivos descritores foi possível a caracterização de cinco ecotipos funcionais, todos eles com composição específica associada a diferentes assembléias de espécies: 1) Nerítico; 2) Camada Oceânica; 3) Myctophidae; 4) Camada Oceânica com Myctophidae; e 5) Nuvem de Quebra (de Plataforma). Os resultados são descritos a seguir e contém o número de milhas em que cada ecotipo funcional ocorreu, de um total de 1.653 milhas náuticas $(\mathrm{mn})$ prospectadas.

\section{1) Nerítico}

O ecotipo funcional Nerítico caracteriza-se por uma homogeneidade tanto vertical quanto horizontal, geralmente ocupando toda a coluna de água. Os aspectos diurno (Figura 2) e noturno (Figura 3) são semelhantes, assinalando-se porém o aumento extremamente significativo da densidade acústica durante os períodos noturnos $(\mathrm{U}=6.557, \mathrm{z}=$ $10,11472, p<0,001)$, sendo que estas diferenças foram observadas em todas as oportunidades em que o ecotipo foi detectado nos diferentes períodos do dia.

Ao longo de $362 \mathrm{mn}$, trajeto que compreendeu praticamente toda a extensão da varredura realizada sobre a plataforma continental da região Nordeste, foram detectados eco-registros do tipo Nerítico, distribuindo-se do limite interno dos perfis até a quebra da plataforma. A profundidade local máxima de ocorrência do ecotipo foi $105 \mathrm{~m}$, valor este que corresponde à máxima extensão vertical registrada para este ecotipo funcional. Um lance de pesca direcionado à amostragem deste tipo de registro capturou principalmente cefalópodes da família Enoploteuthidae, além de teleósteos de pequeno porte das famílias Myctophydae e Bothidae, e larvas Leptocephalus.

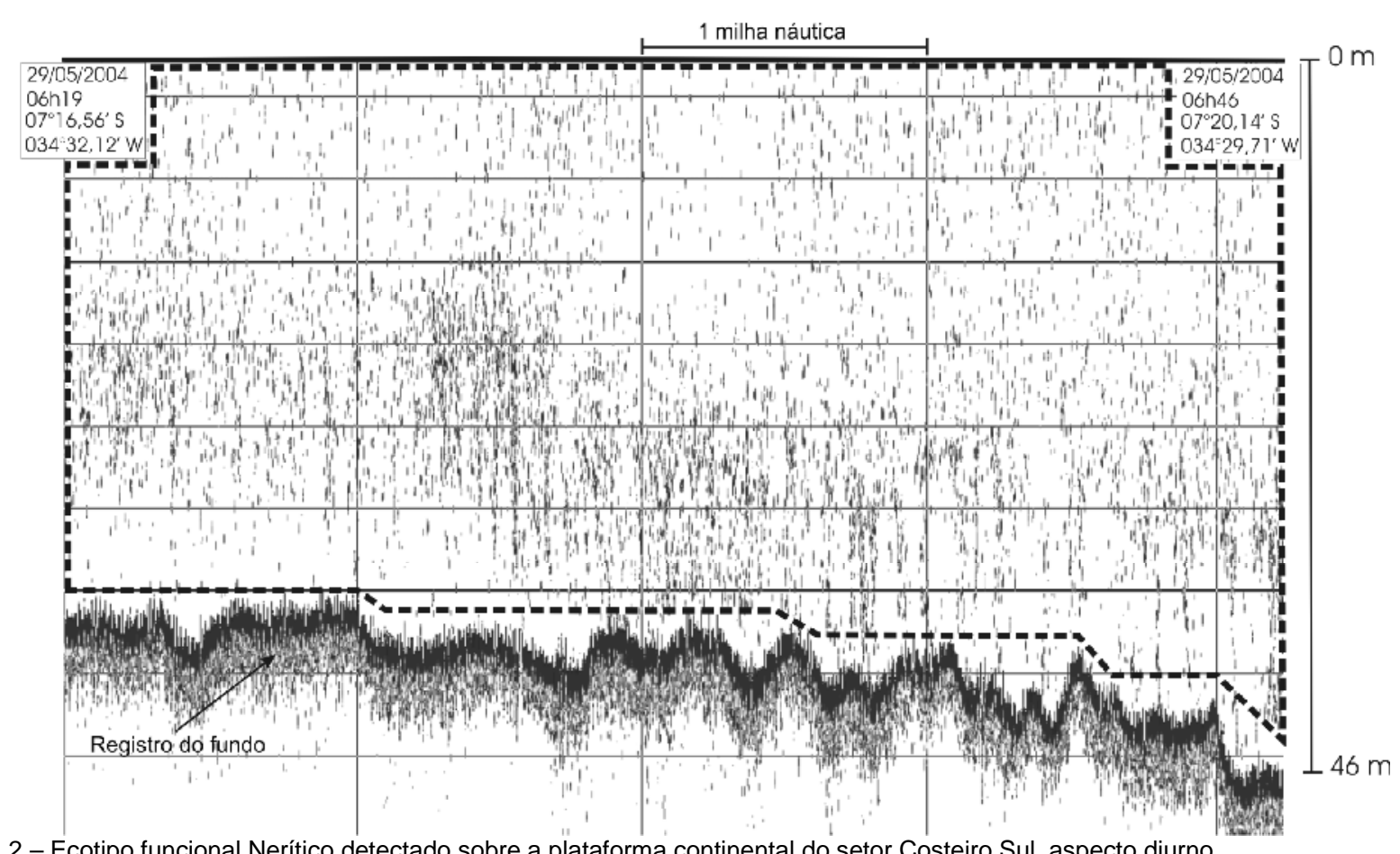

FIGURA 2 - Ecotipo funcional Nerítico detectado sobre a plataforma continental do setor Costeiro Sul, aspecto diurno. 


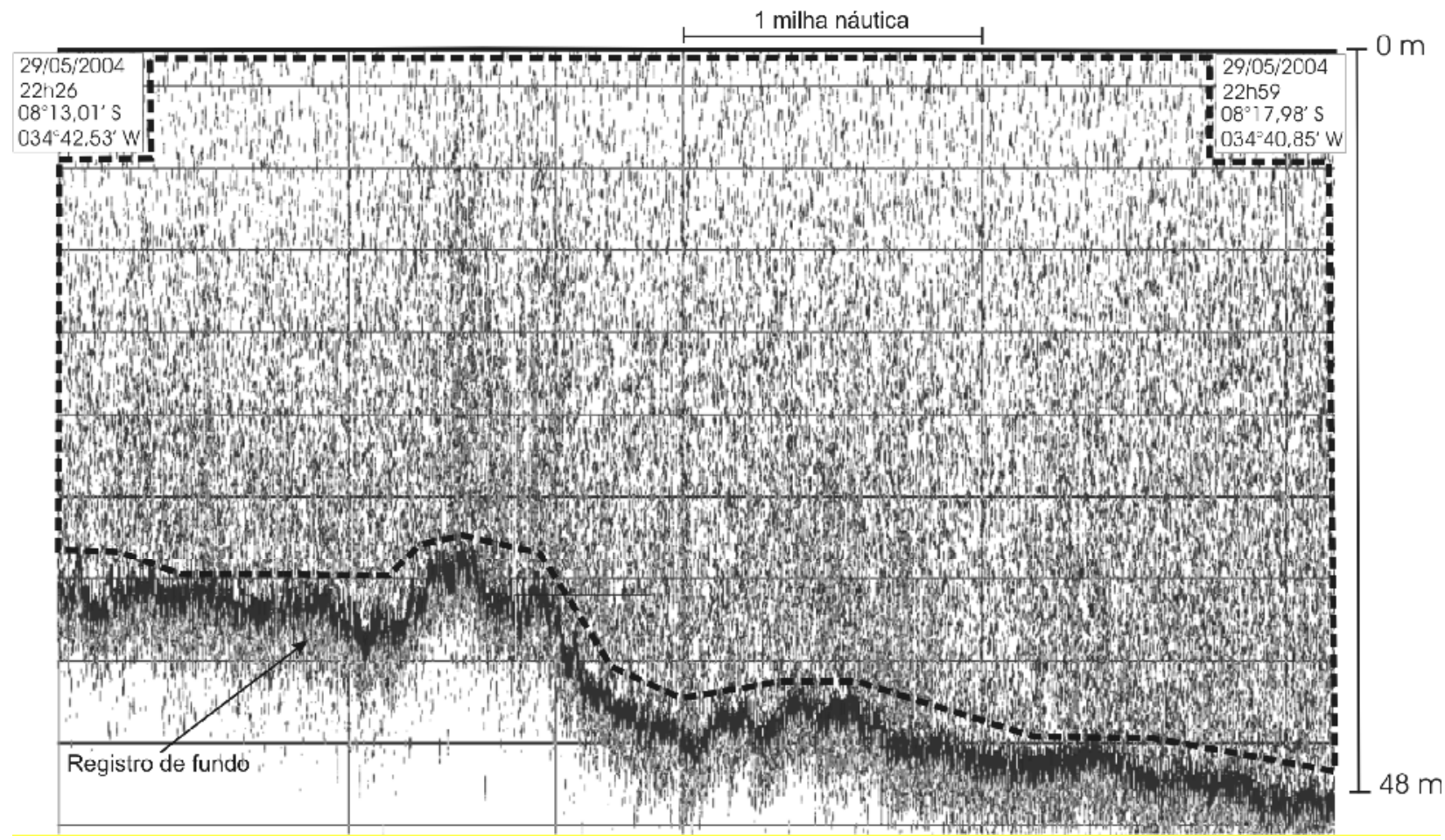

FIGURA 3 - Ecotipo funcional Nerítico detectado sobre a plataforma continental do setor Costeiro Sul, aspecto noturno

\section{2) Camada Oceânica}

Caracteriza-se por uma camada quase homogênea e horizontalmente contínua, que ocupa a porção superior da coluna de água (Figura 4), estendendo-se de muito próximo à superfície até 280 $\mathrm{m}$, valor que corresponde à máxima extensão vertical registrada para este ecotipo funcional.

Registros do tipo Camada Oceânica foram detectados durante o período diurno, ao longo de toda a prospecção acústica realizada nas regiões de talude e oceânicas, numa extensão total de $656 \mathrm{mn}$.
Cinco lances de pesca dirigidos à amostragem deste tipo de registro indicaram uma composição de diferentes espécies de pequenos peixes pelágicos (principalmente famílias Bothidae, Balistidae, Diodontidae e Paralepididae) e mesopelágicos (família Myctophidae), cefalópodes (famílias Enoploteuthidae, Cranchiidae e Ommastrephidae), Euphausiacea e outros crustáceos (famílias Sergetidae e Peneidae), além de tunicados (ordem Doliolida), pterópodos (Cavolinia sp.), e em menor número sifonóforos e heterópodos. 


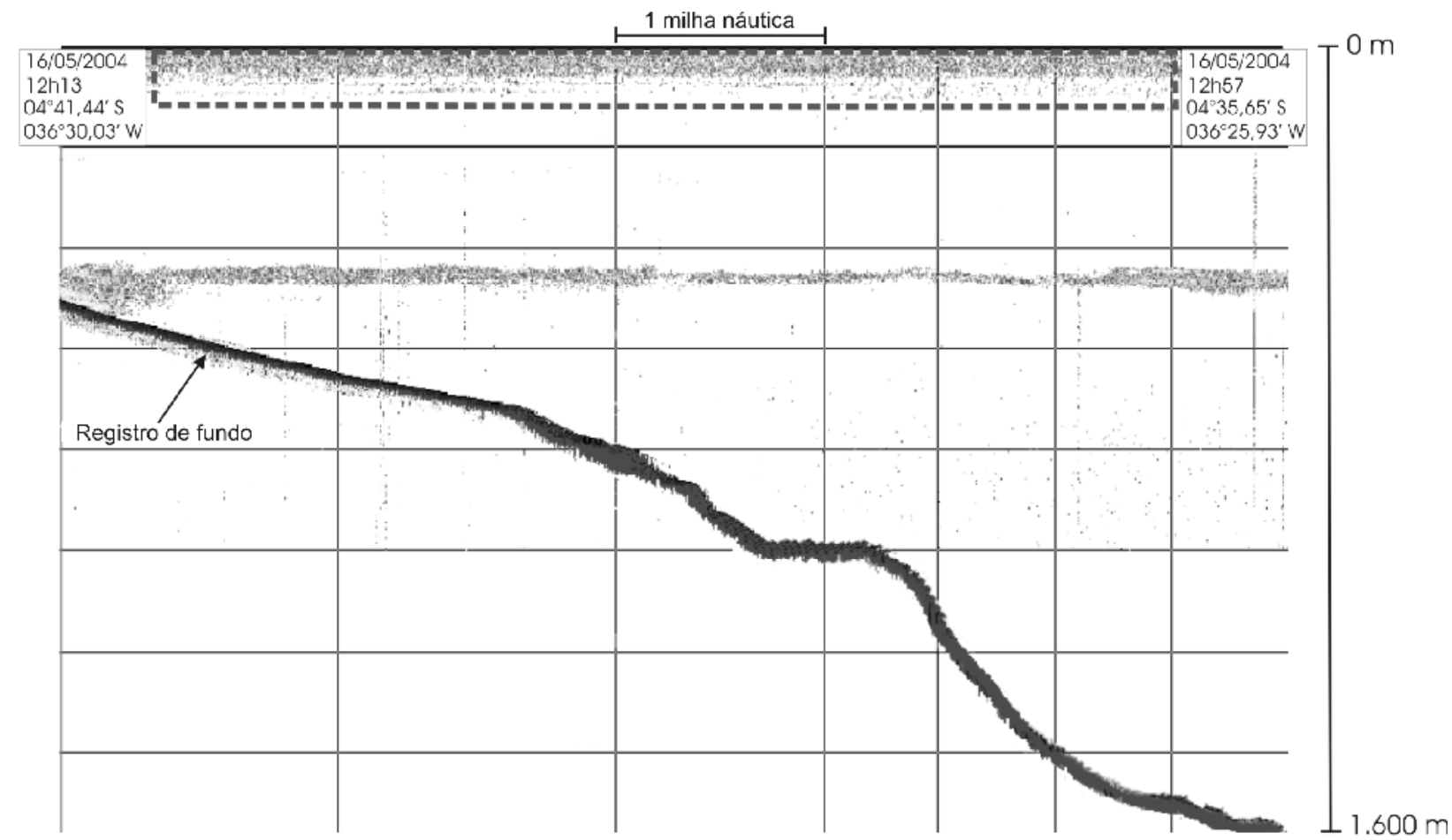

FIGURA 4 - Ecotipo funcional Camada Oceânica detectado sobre o talude do setor Costeiro Norte

3) Myctophidae

Caracterizam-se por formar camadas de dispersão em meia água (em média entre 226 e 658 m de profundidade) durante o período diurno (Figura 5).

Os registros do tipo Myctophidae foram detectados ao longo de toda a área de estudo, nas regiões de talude e oceânicas, perfazendo uma extensão total de $345 \mathrm{mn}$. Em um lance de pesca dirigido à amostragem deste tipo de registro foi capturada uma composição com predomínio de peixes da família Myctophidae, Euphausiacea e pequenas lulas da família Enoploteuthidae.

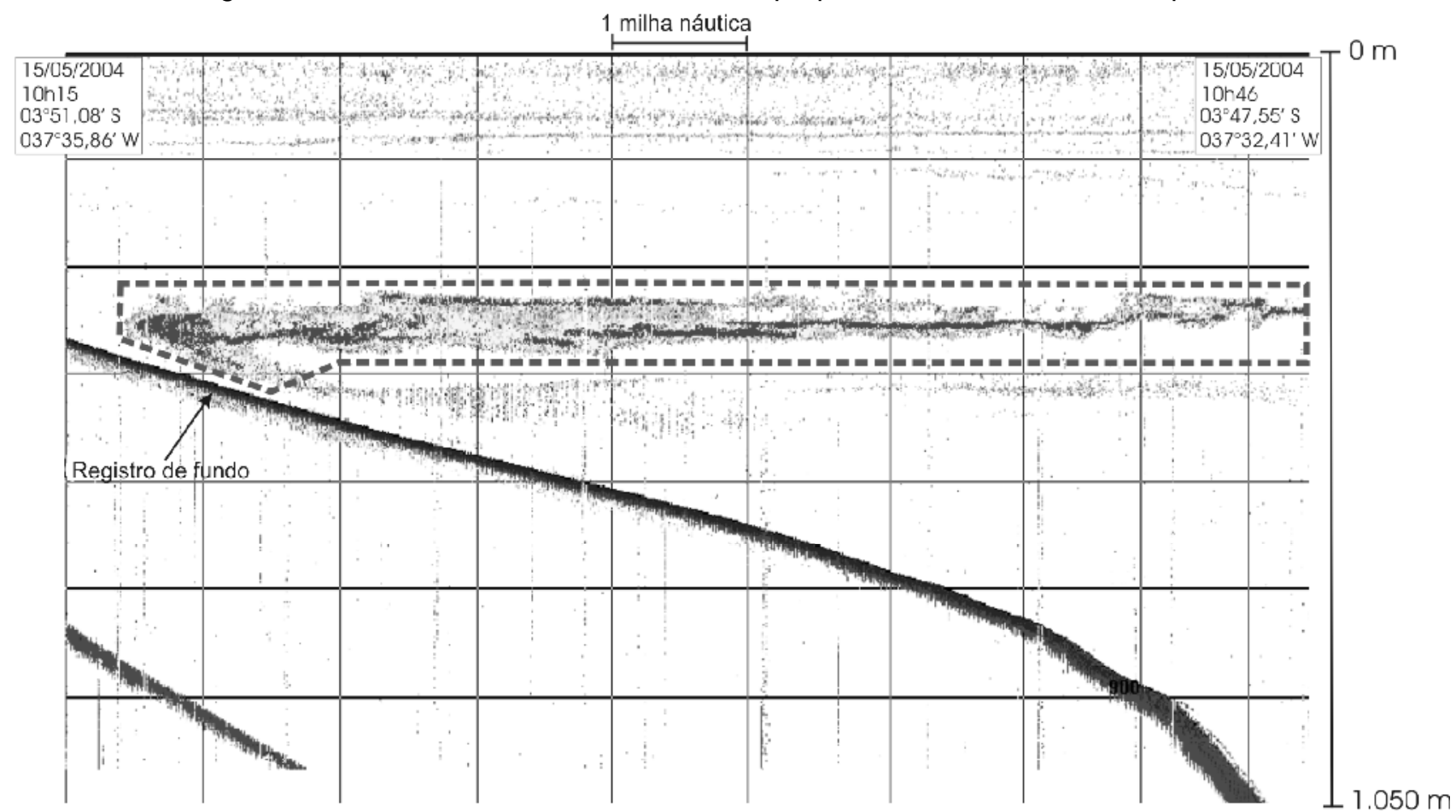

FIGURA 5 - Ecotipo funcional Myctophidae detectado sobre o talude do setor Costeiro Norte. 
Um aspecto comportamental marcante deste ecotipo é a migração nictemeral, quando os organismos que o compõem ascendem para camadas superiores ao entardecer (migração vespertina) e retornam à meia água no amanhecer (migração matutina). Movimentos de migração vertical vespertina (Figura 6) foram observados a partir das 16:26 horas. Em um destes eventos foram analisados horário e profundidade do topo da camada no início e final do registro da migração, resultando em um deslocamento de $252 \mathrm{~m}$ em 46 minutos, indicando um deslocamento médio da ordem de $5,47 \mathrm{~m} / \mathrm{min}$.

Foram também observados e parcialmente registrados eventos de migração matutina, descendente, a partir das 05:00 horas.

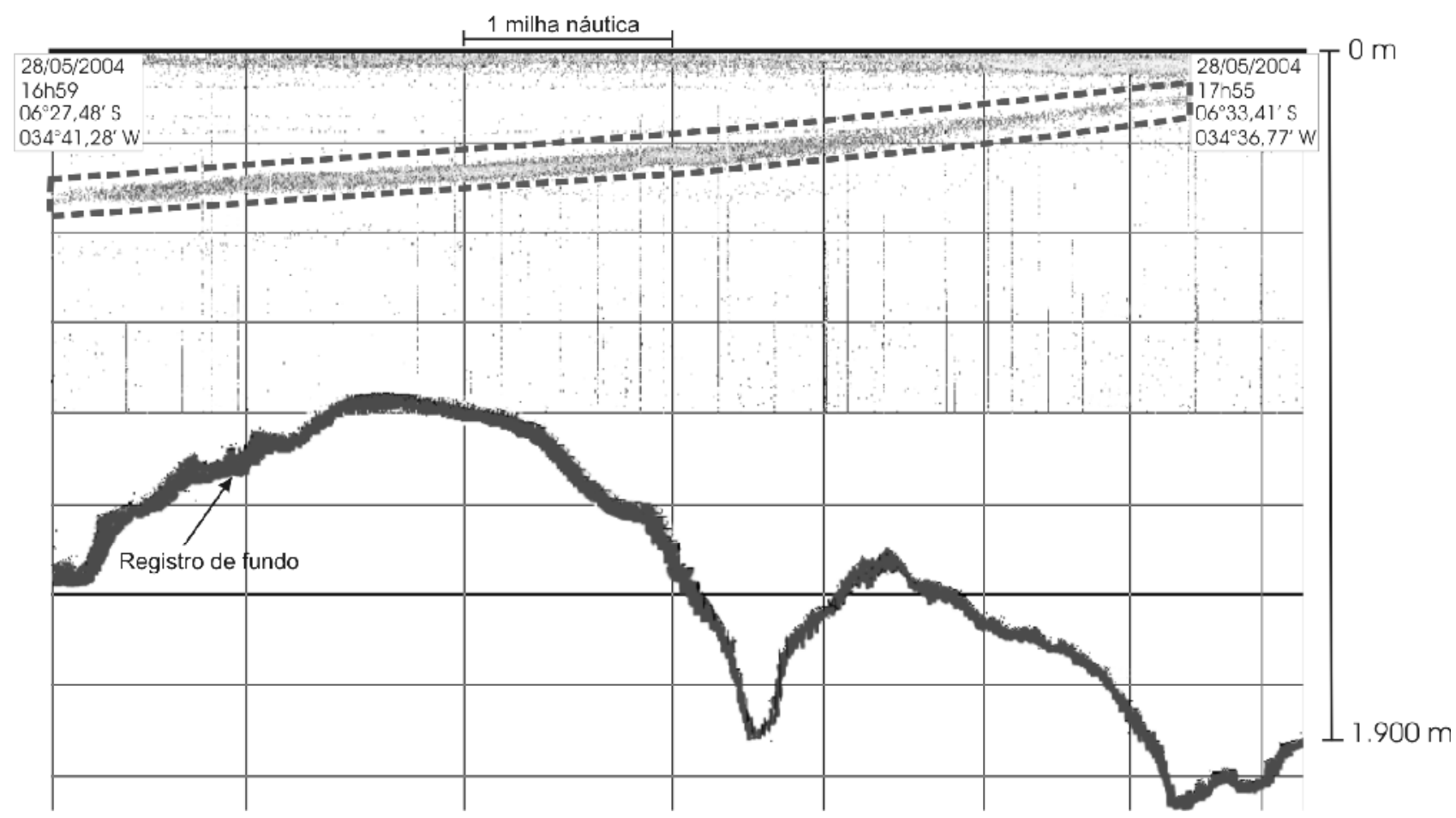

FIGURA 6 - Registro de migração vertical vespertina de organismos componentes do ecotipo funcional Myctophidae, detectado na região oceânica do setor Costeiro Sul.

\section{4) Camada Oceânica com Myctophidae}

Este ecotipo caracteriza-se por uma camada uniforme e relativamente densa, que se estende da superfície até um máximo de $250 \mathrm{~m}$. Corresponde ao principal tipo de registro observado nas regiões de talude e oceânicas no período noturno, após ocorrer a migração vespertina ascendente das chamadas camadas de Myctophidae. As camadas de Myctophidae que migram compõem principalmente a base da camada oceânica tipicamente diurna, incrementando a extensão vertical e densidade acústica da mesma (Figura 7). 


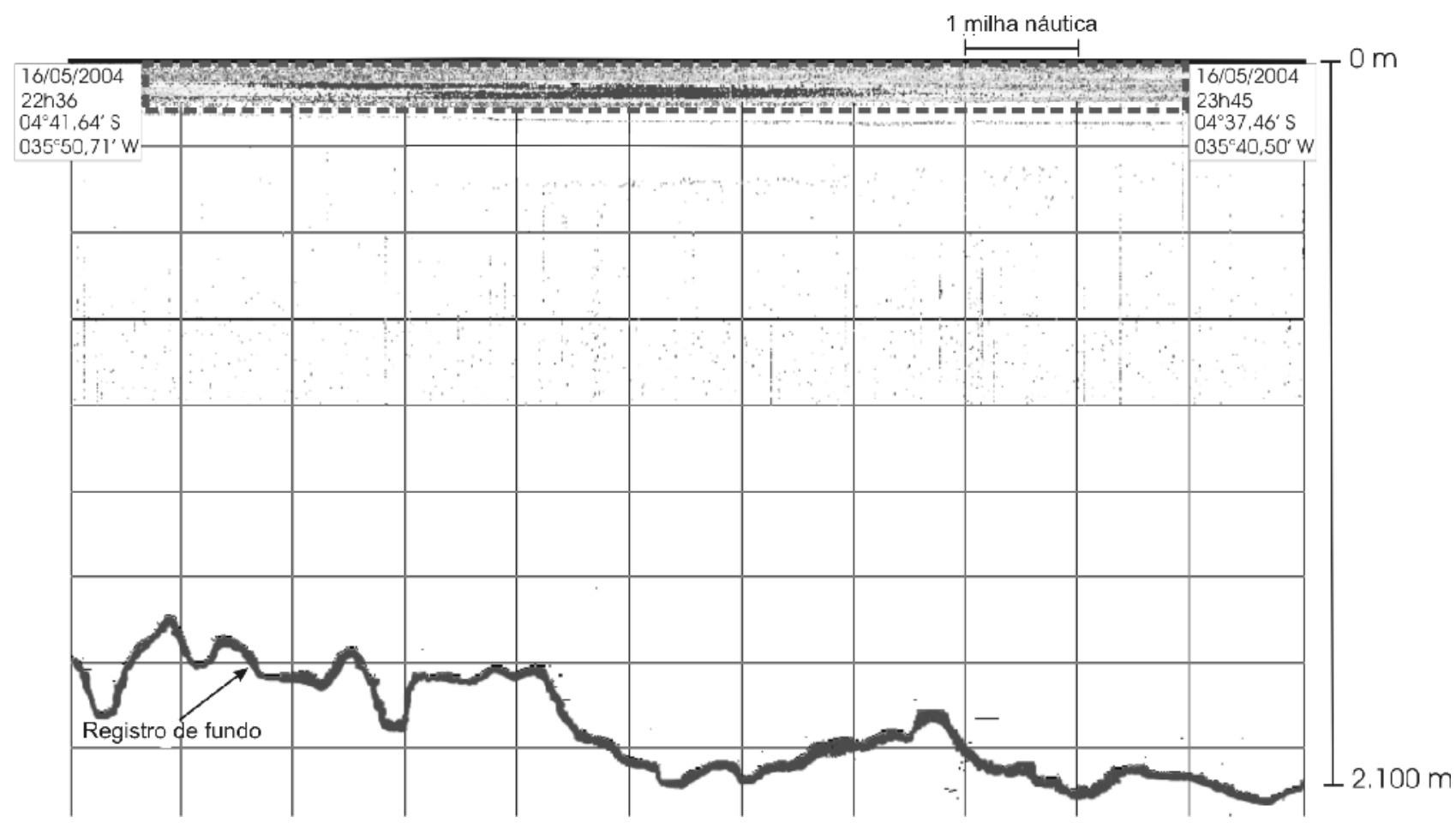

FIGURA 7 - Ecotipo funcional Camada Oceânica com Myctophidae, detectado sobre a região oceânica do setor Costeiro Norte.

Avaliações do parâmetro densidade acústica de organismos (NASC) considerando os diferentes períodos do dia, foram realizadas em duas oportunidades, quando se compararam valores de NASC de um estrato compreendido entre os 5 e $200 \mathrm{~m}$ de profundidade, em uma mesma região geográfica, para os períodos do dia e da noite, separadamente. $\mathrm{O}$ resultado do teste estatístico indicou diferenças significativas $(U=21, z=-6,65265, p<0,001)$ entre os valores de NASC dos dois períodos, sendo que a densidade acústica média foi maior no período noturno, após a migração ascendente dos organismos formadores do ecotipo funcional Myctophidae, configurando o ecotipo funcional Camada Oceânica com Myctophidae, do que no período diurno, quando o estrato em questão era ocupado apenas pelo ecotipo funcional Camada Oceânica.

\section{5) Nuvem de Quebra}

Registros do tipo Nuvem de Quebra caracterizam-se por uma agregação de organismos, na região do talude superior, próximo à quebra da plataforma continental (Figura 8) provocando um súbito aumento na densidade acústica. 


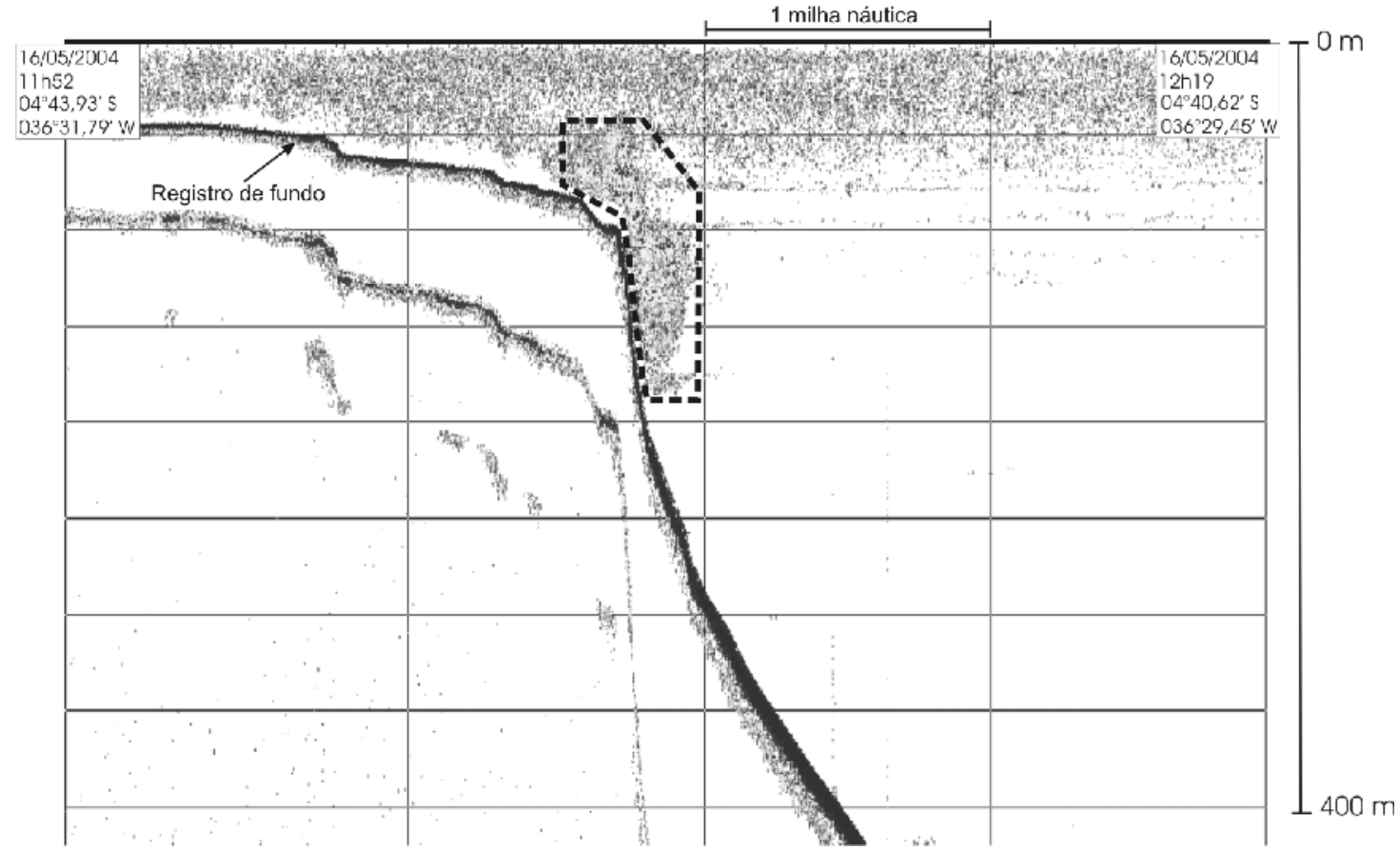

FIGURA 8 - Ecotipo funcional Nuvem de Quebra, detectado na região de quebra de plataforma continental do setor Costeiro Norte.

Este tipo de registro foi detectado ao longo de um total de $60 \mathrm{mn}$, em diferentes períodos do dia. Dois lances de pesca dirigidos à sua amostragem capturaram uma composição de espécies epi e mesopelágicas. Os primeiros representados principalmente por Decapterus tabl, e os segundos com predomínio de peixes da família Myctophidae.

Informações relativas à ocorrência dos cinco ecotipos, e aos descritores espaciais e morfológicos dos mesmos são apresentadas nas tabelas 2 e 3 , respectivamente. O somatório da extensão horizontal dos ecotipos apresenta valores superiores à extensão total da varredura, em todos os setores, devido à sobreposição de ecotipos em uma mesma milha náutica. Este fato foi principalmente observado entre Camada Oceânica e Myctophidae.

TABELA 2 - Ocorrência dos ecotipos em termos de extensão horizontal (mn), em cada setor

\begin{tabular}{lcccccc}
\hline \multirow{2}{*}{ Setor } & \multicolumn{5}{c}{ Extensão horizontal (mn) } & \multirow{2}{*}{ Extensão total da } \\
\cline { 2 - 5 } & $\mathrm{N}$ & $\mathrm{CO}$ & $\mathrm{M}$ & $\mathrm{CM}$ & $\mathrm{NQ}$ & \\
\hline Costeiro Norte & 143,1 & 100,3 & 94,6 & 118,6 & 19,8 & varredura (mn) \\
Costeiro Sul & 218,9 & 172,0 & 105,7 & 200,0 & 23,1 & 381,0 \\
Bancos do Ceará & - & 172,3 & 19,8 & 116,5 & 3,8 & 624,0 \\
Atol das Rocas & - & 53,4 & 14,3 & 40,5 & 6,1 & 288,0 \\
Fernando de Noronha & - & 109,1 & 63,1 & 10,1 & 7,2 & 140,0 \\
São Pedro e São Paulo & - & 49,6 & 47,0 & 26,0 & - & 133,5 \\
\hline Total & 362,0 & 656,7 & 344,5 & 511,7 & 60,0 & 87,0 \\
\hline
\end{tabular}

FONTE: Stefan Cruz Weigert

Ecotipos funcionais da ZEE Nordeste do Brasil; Obs: $\mathrm{N}$ = Nerítico, $\mathrm{CO}=$ Camada Oceânica, $\mathrm{M}=$ Myctophydae, $\mathrm{CM}=\mathrm{Camada}$ Oceânica com Myctophidae e NQ = Nuvem de Quebra. 
TABELA 3 - Principais descritores espaciais e morfológicos dos ecotipos descritos, em cada setor.

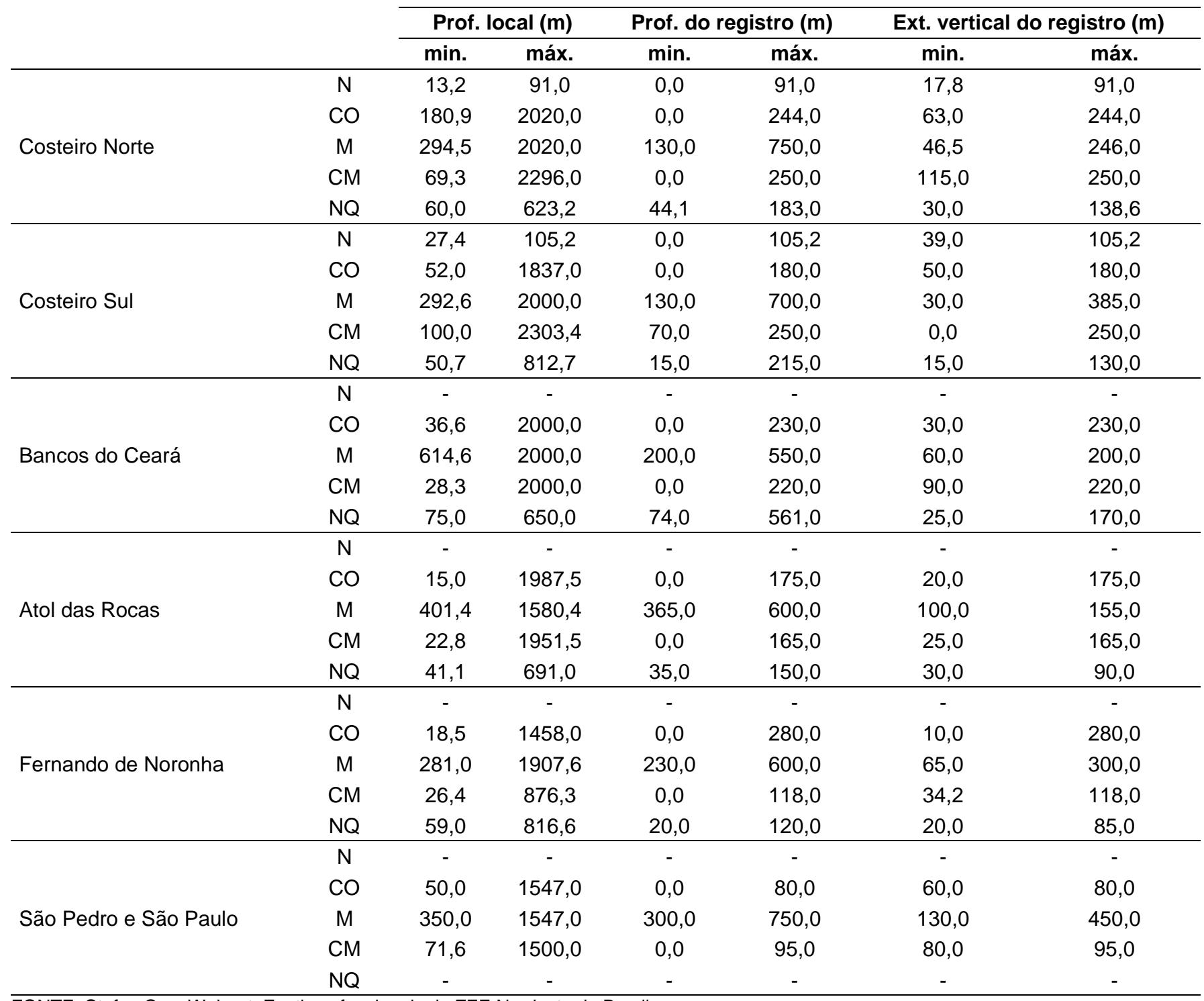

FONTE: Stefan Cruz Weigert; Ecotipos funcionais da ZEE Nordeste do Brasil

Obs: $\mathrm{N}$ = Nerítico, $\mathrm{CO}$ = Camada Oceânica, $\mathrm{M}$ = Myctophydae, $\mathrm{CM}$ = Camada Oceânica com Myctophidae e NQ = Nuvem de Quebra

A análise da distribuição da densidade acústica (NASC) total para os distintos setores da região Nordeste, mostra valores mais elevados nos estratos superiores, compreendidos entre a superfície e os $150 \mathrm{~m}$ de profundidade. No setor Costeiro Norte, $73,7 \%$ do total da densidade acústica esteve contida nesse estrato, $77,9 \%$ no Costeiro Sul, $75,1 \%$ nos Bancos do Ceará, 96,7\% no Atol das Rocas, 93,2\% no Arquipélago de Fernando de Noronha e $52,8 \%$ no Arquipélago de São Pedro e São Paulo (Figura 9). Considerando-se a totalidade dos dados de densidade acústica, para todos os setores, $78,7 \%$ da densidade acústica total esteve contida nos estratos superiores, até os $150 \mathrm{~m}$ de profundidade.
Destaca-se ainda que a densidade acústica decresce até um valor mínimo entre os 150 e 350 m, voltando a aumentar nas camadas mais profundas. Valores de NASC relativamente altos observados no estrato de 400 a $500 \mathrm{~m}$ estão associados à presença de densas camadas de dispersão acústica, classificadas como ecotipo funcional Myctophidae, para todos os setores. Este fenômeno é mais destacado no setor São Pedro e São Paulo onde $28,8 \%$ da densidade acústica total estão contidos no último estrato (figura 9-f), tendo sido registradas camadas de dispersão acústica posicionadas além dos $500 \mathrm{~m}$ de profundidade, até um máximo de cerca de $750 \mathrm{~m}$ de profundidade durante o período diurno. 

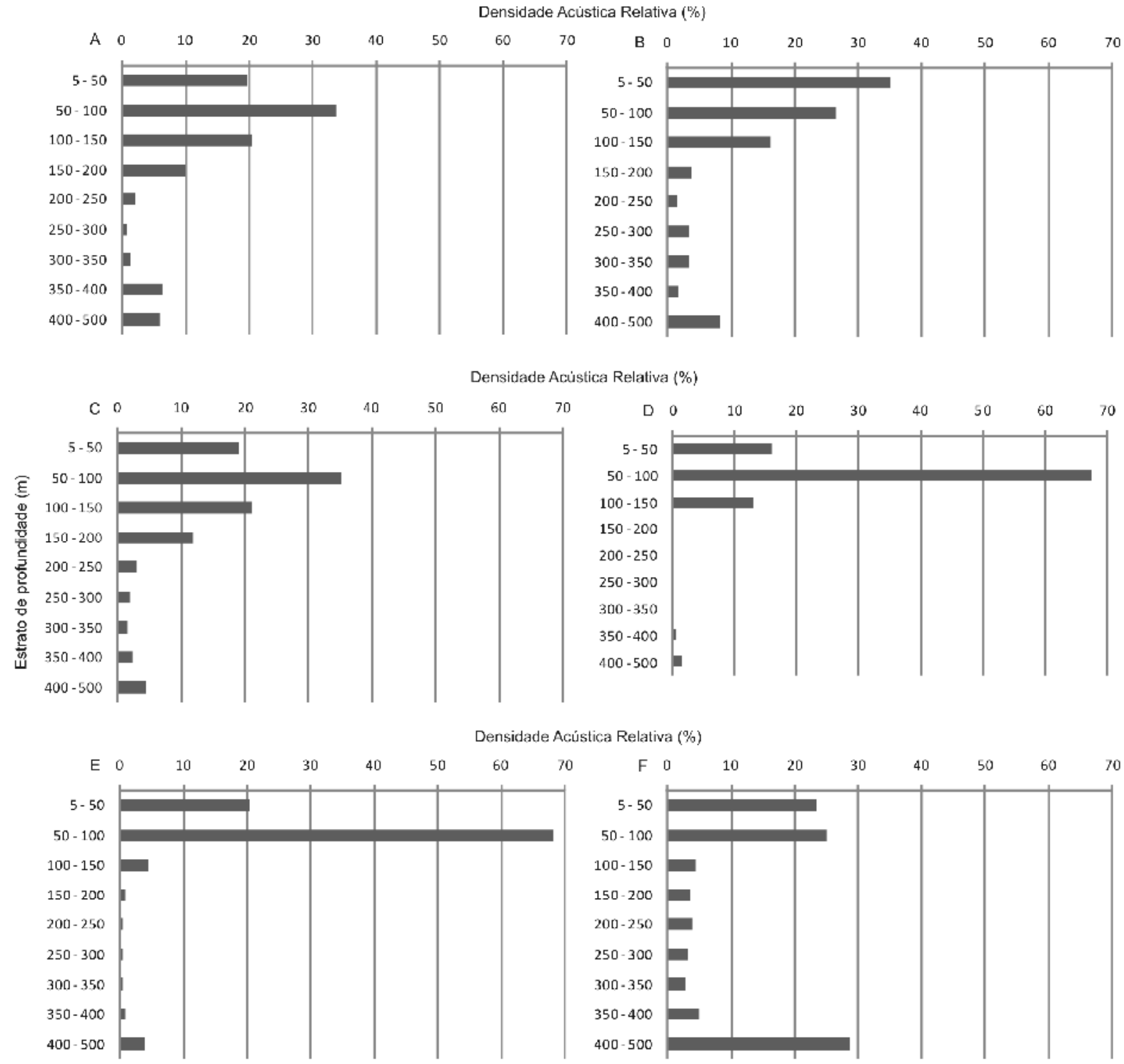

FIGURA 9 - Densidade acústica total relativa (NASC) por estrato de profundidade para os setores Costeiro Norte (A), Costeiro Sul (B), Bancos Oceânicos do Ceará (C), Atol das Rocas (D), Fernando de Noronha (E) e São Pedro e São Paulo (F).

\section{DISCUSSÃO E CONCLUSÕES}

As estruturas mais frequentemente observadas nos ecoregistros do cruzeiro realizado na ZEE da região nordeste do Brasil foram as camadas de dispersão acústica (CDA), detectadas em superfície e meia água ao longo de todas as regiões oceânicas e de talude da área de estudo. Os dados de captura indicam que estas camadas foram principalmente compostas por um elevado número de espécies de organismos do meso, macro e megaplâncton e também micronécton, como pequenas lulas da família Enoploteuthidae além de peixes epi- e mesopelágicos com predomínio da família Myctophidae (Vaske Jr. et al. 2005).
As CDA são amplamente descritas na literatura há muitos anos, sendo observadas em regiões oceânicas e de talude, distribuídas pelos oceanos a nível mundial (Sameoto et al. 1985). As descrições indicam que estas camadas são formadas principalmente por organismos zooplanctônicos (meso, macro e megaplâncton) e pequenos peixes mesopelágicos (Crawford et al. 1992, lida et al.1996, Salvanes \& Kristoffersen 2001).

No presente estudo as CDA foram classificadas em três ecotipos funcionais de ocorrência oceânica: a) Camada Oceânica; b) Myctophidae e; c) Camada Oceânica com Myctophidae. Esta classificação está embasada nas amostragens biológicas realizadas. Cabe ressaltar 
que a rede de arrasto de meia água foi utilizada como amostrador devido aos objetivos do cruzeiro. Considerando-se que rede foi permanentemente monitorada, sem indicativos de operação inadequada, a ocorrência de quatro lances de amostragem com captura nula é um forte indício de escape dos organismos pelas malhas, configurando a presença de espécimes de pequeno porte. Desta forma, assume-se que uma parcela significativa dos organismos componentes das CDA, representada por indivíduos de pequenas dimensões integrantes do meso, macro e megaplâncton e micronécton tenha sido detectada pela ecossonda, porém subamostrada pela rede de arrasto de meia água (Vaske Jr. et al. 2005, Madureira et al. 2009).

O micronécton pelágico compreende organismos com comprimento entre 2 e $20 \mathrm{~cm}$, onde se incluem formas jovens de grandes peixes pelágicos, além de adultos de peixes migrantes verticais, como Myctophidae, Gonostomatidae e outras famílias de peixes do epi-, meso- e batipelagial. Nesse grupo também se enquadram crustáceos, como as formas adultas de hiperídeos e eufausiáceos, e pequenos cefalópodes, como Ommastrephidae, Cranchiidae e Enoploteuthidae.

A ocorrência de extensas camadas de organismos como observadas na ZEE Nordeste, é menos evidente nas regiões Central (Madureira et al. 2004) e Sudeste/Sul do Brasil (Madureira \& RossiWongtschowski 2005). Especula-se que a organização estrutural em camadas, esteja associada à presença de termoclinas permanentes, bem definidas e com marcado gradiente térmico, além da característica oligotrófica das águas da ZEE nordestina (Travassos et al. 1999, Medeiros et al. 2009a).

A ausência de estruturas do tipo cardumes na região Nordeste, comparativamente ao observado em cruzeiros realizados na região Sudeste/Sul brasileira (Madureira \& Rossi-Wongtschowski 2005), é mais um indicativo de que as camadas detectadas pela ecossonda sejam compostas de organismos de pequeno porte, que não formam estruturas com limites bem definidos, como os cardumes observados no caso dos peixes ou mesmo de algumas espécies de eufausiáceos como o krill antártico (Watkins et al. 1986).

Um aspecto comportamental marcante associado ao ecotipo funcional Myctophidae é a migração vertical, deslocando-se de camadas profundas em direção às proximidades da superfície a partir do entardecer (migração vespertina), voltando para camadas profundas ao amanhecer (migração matutina). Tal comportamento migratório fez necessária a diferenciação dos eco registros antes/durante e depois das migrações. Por essa razão o ecotipo funcional Camada Oceânica inexiste à noite, uma vez que o volume de água onde se posicionam os organismos que compõem este registro durante o dia é ocupado, no período noturno, também por organismos que formam o ecotipo funcional Myctophidae.

De acordo com Wootton (1990), as principais hipóteses para explicar as migrações nictemerais são: 1) os indivíduos migram para acompanhar o movimento de suas presas; 2) estratos mais profundos são utilizados durante o dia como refúgio contra a ação de predadores visuais epipelágicos; e 3) águas profundas, de temperaturas mais baixas provocam uma diminuição na taxa metabólica, reduzindo assim gastos energéticos que são compensados durante a alimentação ativa a noite, em águas menos profundas e mais ricas em alimento. Clark \& Levy (1988) apresentaram a hipótese de "janelas de anti-predação" (antipredation window), onde os organismos que migram à superfície durante os períodos crepusculares visam uma combinação entre melhores chances de alimentação e menor risco de predação.

As interações entre presas e predadores e a intensidade luminosa são provavelmente os fatores que induzem às maiores densidades acústicas noturnas no ecotipo Nerítico. Possivelmente grupos de organismos posicionados próximos ao fundo durante o dia dispersem na coluna de água a noite. $\mathrm{A}$ capacidade do equipamento acústico de resolver sinais muito próximos ao fundo é baixa devido ao próprio sinal muito intenso do leito e à denominada "zona morta" (Simmonds \& MacLennan, 2005).

Outros estudos têm demonstrado que os organismos componentes das CDA ao realizarem migrações nictemerais deslocam-se também obliquamente. Nestes movimentos a componente horizontal do deslocamento chega a ter uma ordem de magnitude duas vezes maior do que a vertical (Benoit-Bird \& Au 2004). Com isso, organismos mesopelágicos formadores de camadas associadas a ilhas e regiões de quebra de plataforma continental 
podem ser encontrados em águas rasas, sobre a plataforma, no período noturno, promovendo assim uma ligação entre ecossistemas através da transferência de energia na forma de biomassa (Benoit-Bird et al. 2001).

Agregações biológicas, associadas com as regiões de quebra da plataforma continental ou de topo das feições geomorfológicas foram observadas em todos os setores da costa Nordeste, à exceção do setor São Pedro e São Paulo. Esses registros foram classificados como ecotipo Nuvem de Quebra, estando sua composição específica associada a espécies epipelágicas (sobretudo Decapterus tabl) e mesopelágicas (peixes da família Myctophidae). Madureira et al. (2004) descreveram a presença de cardumes característicos, compostos por Decapterus tabl, associados aos taludes dos bancos oceânicos da costa Central do Brasil, formando uma espécie de "coroa" em torno dos mesmos.

Considerando-se que a mesma metodologia de classificação de eco-registros em ecotipos funcionais foi utilizada em diversos setores da costa brasileira é interessante observar que na região Nordeste foram identificados os cinco tipos ora apresentados enquanto na região Central foram classificados nove, e na região Sudeste/Sul seis diferentes ecotipos (Madureira et al. 2004, Madureira \& Rossi-Wongtschowski 2005). Estas observações levam a sugerir que a região Central contenha agregações comuns ao Sudeste/Sul e ao Nordeste. Enquanto que na região Sudeste/Sul, as biomassas são várias ordens de magnitude maiores do que nas demais regiões, e a diversidade é menor (Madureira \& Rossi-Wongtschowski 2005), no Nordeste, com a menor biomassa, a ausência de cardumes elimina os ecotipos associados a este tipo de estruturas (Madureira et al 2009).

As densidades acústicas observadas nos diferentes estratos de profundidade indicam uma concentração biológica maior entre a superfície e os $150 \mathrm{~m}$, em todos os setores. Esta camada superior corresponde à água superficial de mistura e compreende a marcada termoclina permanente da região (Weigert 2006, Madureira et al. 2009, Medeiros et al. 2009a). Pinot \& Jansá (2001) apresentam indícios de associação entre a densidade de organismos planctônicos e a presença e profundidade da termoclina, observando decréscimo de densidade para águas imediatamente abaixo desta. Os resultados obtidos nesse trabalho em parte corroboram as observações destes autores.

Por outro lado, os resultados também indicam uma tendência de aumento da densidade acústica nas camadas mais profundas (350 a $500 \mathrm{~m}$ ), para todos os setores. Estas densidades mais altas estão associadas a organismos cujos registros são característicos de CDA de peixes mesopelágicos, aqui classificadas como o ecotipo Myctophidae. Os organismos componentes desse ecotipo apresentam natação ativa e realizam extensas migrações nictemerais, rompendo a barreira imposta pela termoclina, estabelecendo assim um importante elo ecotrófico entre os ambientes pelágicos superficial e profundo. Deve ser observado ainda que diferentes espécies de predadores pelágicos de topo apresentam limites verticais de distribuição distintos, impostos principalmente por baixas temperaturas e/ou mínimos de oxigênio dissolvido na água, de modo que algumas não mergulham abaixo da termoclina e, consequentemente, se beneficiam dos movimentos verticais de suas presas (Evans et al. 1981, Bertrand et al. 2002, Brill et al. 2005).

Vaske Jr. et al. (2008) avaliando o conteúdo estomacal de indivíduos de palombeta-do-Caribe (Brama caribbea), uma das presas mais abundantes dos grandes predadores pelágicos da ZEE nordestina, encontraram uma similaridade de $86,8 \%$ entre os conteúdos estomacais da espécie e a composição das capturas com rede de meia água realizadas no cruzeiro objeto do presente estudo. Os principais itens alimentares foram Euphausiacea, hiperídeos, os peixes Myctophidae e Acanthurus sp., os cefalópodes Enoploteuthidae, Cranchiidae e Ommastrephidae, e heterópodes. Os autores indicaram a palombeta-doCaribe como importante elo de ligação entre os organismos micronectônicos e os predadores de topo, sendo os Euphausiacea e Myctophidae considerados o principal item alimentar da palombeta-do-Caribe e, portanto, grupos chave na transferência de energia entre os diferentes níveis tróficos.

No presente estudo a organização dos ecoregistros permitiu avaliar aspectos comportamentais, de distribuição espaço-temporal assim como de abundância, dos organismos que os compõe. Os resultados de Vaske Jr. et al. (2008) associam dietas 
de predadores de nível secundário, predados por grandes pelágicos, aos organismos identificados nos registros. Futuros estudos que venham a investigar as interações tróficas da ZEE do Nordeste do Brasil deverão ater-se a amostragem biológica e estudos de dietas de forma a buscar um acoplamento entre principais áreas de ocorrência de presas e, por consequência, de seus predadores.

\section{AGRADECIMENTOS}

À Coordenação do Score-Nordeste, à Coordenção do Programa REVIZEE e ao CNPq/MCT.

Ao Comandante Homero Pojeaux Alvariza e equipe pela competência durante a execução dos trabalhos.

Às equipes dos Laboratórios de Tecnologia Pesqueira e Hidroacústica (FURG) e de Dinâmica de Populações Marinhas (UFRPE).

Aos Professores Doutores Marcelo Cunha Vasconcellos e Gonzalo Velasco Canziani pela correção, críticas e sugestões.

\section{REFERÊNCIAS}

BECKER, M. 2001. Caracterização física e química dos Bancos e Ilhas oceânicas do Nordeste brasileiro, uma contribuição ao Programa REVIZEE. Tese de Doutorado. Universidade Federal de São Carlos. $180 p$.

BENOIT-BIRD, KJ, WWL AU, RE BRAINARD \& MO LAMMERS. 2001. Diel horizontal migration of the Hawaiian mesopelagic boundary community observed acoustically. Mar. Ecol. Prog. Ser. 217: 1-14.

BENOIT-BIRD, KJ \& WWL AU. 2004. Diel migration dynamics of na island-associated sound-scattering layer. Deep-Sea Res. I, 51: 707-719.

BERTRAND, A, E JOSSE, P BACH, P GROS \& L DAGORN. 2002. Hydrological and trophic characteristics of tuna habitat: consequences on tuna distribution and longline catchability. Can. J. Fish. Aquat. Sci., 59(6): 1002-1013.

BRILL, RW, KA BIGELOW, MK MUSYL, KA FRITSCHES \& EJ WARRANT. 2005. Bigeye tuna (Thunnus obesus) behaviour and physiology and their relevance to stock assessments and fishery biology. Collect. Vol. Sci. Pap., ICCAT, 57(2): 142-161.

CARTES, JE. 1994. Influence of depth and season on the diet of deep-water arrested Aristeus anttenatus along the continental slope $(400-2300 \mathrm{~m})$ in the Catalan Sea (Western Mediterranean). Mar. Biol., 120: 639-648.

CARTES, JE, M HIDALGO, $V$ PAPIOL, E MASSUTI \& J MORANTA. 2009. Changes in the diet and feeding of the hake Merluccius merluccius at the shelf-break of the Balearic Islands: Influence of the mesopelagic-boundary community. Deep-Sea Res. I, 56: 344-365.

CASTELLO, JP, RP HABIAGA, JC AMARAL \& ID LIMA Jr. 1991. Prospecção hidroacústica e avaliação de biomassa de sardinha e anchoita, na Região Sudeste Sul do Brasil (outubro/novembro de 1998). Publ. Esp. Inst. Oceanogr., 8: 15-29.
CASTELLO, JP. 1997. A Anchoita (Engraulis anchoita, Engraudidae, Pisces) no sul do Brasil. Tese de doutorado. Universidade Federal do Rio Grande. 84 p.

CASTRO, BM \& LB MIRANDA. 1998. Physical Oceanography of the Wester Atlantic Continental Shelf Located Between $4^{\circ} \mathrm{N}$ and $34^{\circ}$ S - Coastal Segment (4, W). In: ROBINSON, AR \& KH BRINK (eds.). The Sea. New York, John Wiley \& Sons, Inc., 11: 209-251.

CLARK, C \& D LEVY. 1988. Diel vertical migrations by juvenile sockeyesalmon and the antipredatin window. Am. Naturalist., 131(2): 271-290.

CLARKE, TA. 1973. Some aspects of the ecology of lanternfishes (Myctophidae) in the Pacific Ocean near Hawaii. Fish Bull., 71: 401-434.

CRAWFORD, RE, C HUDON \& DG PARSONS. 1992. An acoustic study of shrimp (Pandalus montagui) distribuition near Resolution Island (eastern Hudson Strait). Can. J. Fish. Aquat. Sci., 49: 842-856.

EKAU, W \& B KNOPPERS. 1999. An introduction to the pelagic system of the North-East and East Brazilian shelf. Arc. Fish. Mar. Res. 47(2): 113-132.

EVANS, RH, DR MCLAIN \& RA BAUER. 1981. Atlantic skipjack tuna: influences of the environment on their vulnerability to surface gear. Mar. Fish. Rev. 43(6): 1-11.

FERREIRA, AG \& P TRAVASSOS. 2009. Sensoriamento Remoto. In: HAZIN, FHV. Meteorologia e Sensoriamento Remoto, Oceanografia Física, Oceanografia Química e Oceanografia Geológica. Programa REVIZEE - Score Nordeste. Fortaleza, Editora Martins \& Cordeiro, vol. 1: 9-39.

FOCK, HO, B MATTHIESSEN, H ZIDOWITZ \& $H$ VON WESTERNHAGEN. 2002. Diel and habitat-dependent resource utilization by deep-sea fishes at the Great Meteor seamount: niche overlap and support for the sound scattering layer interception hypothesis. Mar. Ecol. Prog. Ser., 244: 219-233.

FOOTE, GK. 1982. Optimizing copper spheres for precision calibration of hydroacoustic equipment. J. Acoust. Soc. Am., 71: 742-747.

GEBER, FO. 2003. Dinâmica de sistemas de bancos oceânicos da Cadeia Norte do Brasil: caracterização experimental e simulação numérica. Dissertação de Mestrado. Universidade Federal de Pernambuco. $114 \mathrm{p}$.

GERLOTTO, F \& E MARCHAL. 1985. The concept of acoustic population as an aid for biomass identification. Tromsö, ICES/FST Working Group Meet. $7 \mathrm{p}$.

GERLOTTO, F. 1993. Identification and spatial stratification of tropical fish concentrations using acoustic population. Aquat. Living Resour., 6: 243-254.

GORDON, JDM \& J MAUCHLINE. 1990. Depth-related in diet of a deep-sea bottom-living fish assemblage of the Rockall trough. In: BARNES, M \& RN GIBSON (eds.). Trophic Relationships in the Marine Environment. Proceedings of the 24th Euroropean Marine Biological Symposyum. Aberdeen University Press, 439-452.

GOSS, C, D MIDDLETON \& P RODHOUSE. 2001. Investigations of squid stocks using acoustic survey methods. Fish. Res., 54: 111-121.

IIDA, K, T MUKAI \& D HWANG. 1996. Relationship between acoustic backscattering strength and density of zooplankton in the sound scattering layer. ICES J. Mar. Sci., 53: 507-512. 
LIMA, ID \& JP CASTELLO. 1994. Distribuición y abundancia de Engraulis anchoita en la costa sur de Brasil. Montevideo, Frente Mar. 15: 87-100.

LONGHURST, AR. 1976. Vertical Migration. In: CUSHING, DH \& JJ WALSH (eds.). The ecology of the Seas. London, Blackwell. 116-137.

MACLENNAN, DN, PG FERNANDES \& J DALEN. 2002. A consistent approach to definitions and symbols in fisheries acoustics. ICES J. Mar. Sci. 59: 365-369.

MADUREIRA, LSP, RP HABIAGA, A GONÇALVES, AB GREIG, AC DUVOISIN, CF SOARES, IY FUSE, FG CALDEIRA, LR CARVALHO, SC WEIGERT, PA SALDO \& CS FERREIRA. 2004. Prospecção de recursos pelágicos por método hidroacústico na plataforma, talude e região oceânica da costa Central do Brasil. Série Documentos Técnicos do Programa REVIZEE - Score Sul. São Paulo, Instituto Oceanográfico USP. 56 p.

MADUREIRA, LSP \& CLDB ROSSI-WONGTSCHOWSKI. 2005. Prospecção de recursos pesqueiros pelágicos na Zona Econômica Exclusiva da Região Sudeste-Sul do Brasil: hidroacústica e biomassas. Série de Documentos Técnicos do Programa REVIZEE - Score Sul. São Paulo, Instituto Oceanográficos - USP. $144 \mathrm{p}$.

MADUREIRA, LSP, RP HABIAGA, CF SOARES, SC WEIGERT, CS FERREIRA \& MP PINHO. 2009. Levantamento Hidroacústico da ZEE do Nordeste - Brasil. In: HAZIN, FHV. Prospecção Pesqueira Hidroacústica da Região Nordeste. Programa REVIZEE - Score Nordeste. Fortaleza, Editora Martins \& Cordeiro, vol. 3: 49-110.

MATSUURA, Y, JC AMARAL, G SATO \& STJ TAMÁSSIA. 1985. Ocorrência de peixes pelágicos e estrutura oceanográfica da região entre Cabo de São Tomé (RJ) e Cananéia (SP), em janeiro/fevereiro de 1979. Série Doc. Técnicos no 33. Brasília. Ministério da Agricultura, SUDEPE/PDP. 67 p.

MAUCHLINE, J \& JDM GORDON. 1991. Oceanic pelagic prey benthopelagic fish in the benthic layer of a marginal oceanic region. Mar. Prog. Ser., 74: 109-115.

MEDEIROS, C, SJ MACÊDO, NA FEITOSA \& ML KOENING. 1999. Hydrography and phytoplankton biomass and abundance of North-East Brazilian Waters. Arc. Fish. Mar. Res., 47(2): 133-151.

MEDEIROS, C, M ARAÚJO, M ROLLNIC \& I FREITAS. 2009a. Estrutura termohalina da região oeste do Atlântico tropical ZEE/NE. In: HAZIN, FHV. Meteorologia e Sensoriamento Remoto, Oceanografia Física, Oceanografia Química e Oceanografia Geológica. Programa REVIZEE - Score Nordeste. Fortaleza, Editora Martins \& Cordeiro, vol. 1: 40-55.

MEDEIROS, C, M ARAÚJO, I FREITAS \& M ROLLNIC. 2009b. Massas d'água da região oeste do Atlântico tropical. In: HAZIN, FHV. Meteorologia e Sensoriamento Remoto, Oceanografia Física, Oceanografia Química e Oceanografia Geológica. Programa REVIZEE - Score Nordeste. Fortaleza, Editora Martins \& Cordeiro, vol. 1: 56-69.

MITSON, RB. 1983. Fisheries sonar. Farnham, Fishing News Books Ltd. $287 \mathrm{p}$.

MOZGOVOY, VA \& VE BEKKER. 1991. Volume sound scattering and the composition of sound-scattering layers in the Canary Basin region. Oceanol. Acad. Sci. USSR, 31: 293-298.

NEUMANN-LEITÃO, S, LMO GUSMÃO, TA SILVA, DA NASCIMENTO-VIEIRA \& AP SILVA. 1999. Mesozooplankton biomass and diversity in coastal and oceanic waters off Northeastern Brazil. Arc. Fish. Mar. Res., 47(2): 153-165.

NONAKA, RH, Y MATSUURA \& K SUZUKI. 2000. Seasonal variation in larval fish assemblages in relation to oceanographic conditions in the Abrolhos Bank region off eastern Brazil. Fish. Bull., 98(4): 767-784.

PETERSON, RG \& L STRAMMA. 1991. Upper level circulation in the South Atlantic. Ocean. Prog. Oceanogr. 26: 1-73.

PETITGAS, P, \& J LEVENEZ. 1996. Spatial organization of pelagic fish: echogram structure, spatio-temporal condition, and biomass in Senegalese waters. ICES J. Mar. Scie., 53: 147153.

PINOT, JM \& J JANSÁ. 2001. Time variability of acoustic backscatter from zooplankton in the Ibiza Channel (western Mediterranean). Deep-Sea Res. I, 48: 1651-1670.

PUSCH, C, A BECKMANN, FM PORTEIRO, HV WESTERNHAGEN. 2004. The influence of seamounts on mesopelagic fish communities. Arc. Fish. Mar. Res., 51(1): 165186.

RAHN, E \& A SANTOS. 1978. Pesca exploratória de lulas (Loligo spp) e calamares (Illex argentinus) nas costas de Santa Catarina e Rio Grande do Sul. Relatório-Síntese no 5 "Mestre Jerônimo". Brasília, Ministério da Agricultura - SUDEPE/PDP. 1 - 39.

RASMUSSEN, OI \& J GISKE. 1994. Life-history parameters and vertical distribution of Maurolicus muelleri in Masfjorden in summer. Mar. Biol., 120(4): 649-664.

REID, SB, J HIROTA, RE YOUNG \& LE HALLACHER. 1991. Mesopelagic-boundary community in Hawaii: micronekton at the interface between neritic and oceanic ecosystems. Mar. Biol., 109: 427-440.

REID, D, C SCALABRIN, P PETITGAS, J MASSE, R AUKLAND, P CARRERA, \& S GEORGAKARAKOS. 2000. Standard protocols for the analysis of school based data from echo sounder surveys. Fish. Res., 47: 125-136.

RIJAVEC, L \& JC AMARAL. 1977. Distribuição e abundância de peixes pelágicos na costa sul e sudeste do Brasil. (Resultados da pesquisa com ecointegrador). Série Documentos Técnicos no24. Brasília, Ministério da Agricultura - SUDEPE/PDP. 86 p.

SALVANES, AG \& JB KRISTOFFERSEN. 2001. Mesopelagic Fishes. In: STEEL, J, S THORPE \& K TUREKIAN (eds.). Encyclopedia of Ocean Sciences. San Diego, Academic Press, 1711-1717.

SAMEOTO, DD, NA COCHRANE \& AW HERMANN. 1985. Response of biological acoustic backscattering to ship's lights. Can. J. Fish. Aquat. Sci., 42: 1535-1543.

SILVA, LCF \& JB ALVARENGA. 1996a. Oceanografia física: região Nordeste. In: Levantamento do estado da arte da pesquisa dos recursos vivos marinhos do Brasil. Brasília, MMA/SMA Programa REVIZEE. $99 \mathrm{p}$.

SILVA, LCF \& JB ALVARENGA. 1996b. Oceanografia física: região Central. In: Levantamento do estado da arte da pesquisa dos recursos vivos marinhos do Brasil. Brasília, MMA/SMA Programa REVIZEE. $96 \mathrm{p}$.

SILVEIRA, ICA, ACK SCHMIDT, EJD CAMPOS, SS GODOI \& $Y$ IKEDA. 2000. The Brazil Current off the Eastern Brazilian Coast. Rev. Bras. Oceanog. 48(2): 171-183.

SIMMONDS, EJ \& DN MACLENNAN. 2005. Fisheries acoustics Theory and Practice. Second Edition, Fish and Aquatic Resources Series 10. London. Chapman \& Hall. 437 p. 
STRAMMA, L. 1991. Geostrophic transport of the South Equatorial Current in the Atlantic, J. Mar. Res. 49: 281-294.

STRAMMA, L \& F SCHOTT. 1999. The mean flow field of the tropical Atlantic ocean. Deep-Sea Research, 46: 279-304.

TRAVASSOS, PEPF, FHV HAZIN, JR ZAGAGLIA, RA ROCHA \& J SCHOBER. 1999. Thermohaline structure around seamounts and islands off Northeast Brazilian coast. Arc. Fish. Mar. Res., 47(2): 211-222.

VASKE JR., T, RP LESSA, A MONTEIRO, JL BEZERRA JR, ACB RIBEIRO, L YOKOTA, KC MOURA, K LOPEZ \& JP FIRMINO. 2005. Programa de Prospecção Acústica do Nordeste do Brasil (Levantamento da fauna com rede de meia água). Relatório Final. $54 \mathrm{p}$.

VASKE JR., T, RP LESSA, TM BARBOSA, MT TOLOTTI \& ACB
RIBEIRO. 2008. Stomach contents of the Caribbean pomfret Brama caribea (Mead 1972) from stomach contents of great pelagic predators from southwestern equatorial Atlantic. B. Inst. Pesca, 34(2): 241-249.

WATKINS, JL, DJ MORRIS, C RICKETS, \& J PRIDDLE. 1986. Differences between swarms of Antarctic krill and some implications for sampling krill populations. Mar. Biol., 93: 137-146.

WEIGERT, SC. 2006. Avaliação hidroacústica dos efeitos causados por bancos submarines e ilhas sobre a distribuição e densidade acústica de organismos pelágicos na Zona Econômica Exclusiva das regiões Central e Nordeste do Brasil. Dissertação de Mestrado. Universidade Federal do Rio Grande. 114 p.

WOOTTON, RJ. 1990. Ecology of teleost fishes. Fish and Fisheries Series 1. London, Chapmann and Hall. 404p. 